\title{
Clinical implications of psychiatric genetics in the new millennium - nightmare or nirvana?
}

We are on the verge of major advances in understanding the pathophysiology of major mental illnesses including the likely discovery of several susceptibility genes for these conditions. For many this holds the prospect of a future in which improved prevention and better treatments will end the terror these conditions hold over so many lives (Farmer \& Owen, 1996; Jones \& Craddock, 1997, 1998). For others the vision is of a 'brave new world', our futures mapped from birth by the genetic hand we have been dealt and in which those with mental illness will suffer increased stigma and discrimination (Rose, 1998). This debate (McGleenan, 1995) occurs in the dark shadow cast by the eugenic movements of the 19th and early 20th century (Galton, 1943) and the horrors to which they led (Hanauske-Abel, 1996; Seidelman, 1996). As we leave the decade of the brain and enter the new millennium it is an appropriate point to ask what advances are likely to occur and to consider the moral and ethical issues that will undoubtedly arise.

\section{Challenges facing psychiatry}

Despite a revolution in the practice of psychiatry over the past 100 years, a number of challenges remain. Diagnostic uncertainties are common and prognostic prediction is poor. The number and cost of new drugs increases year-on-year but treatment response is variable and unpredictable. The debate regarding the optimal environment for the delivery of services rages on with the balance between hospital, local community and home treatment still unresolved. These concerns, although undoubtedly important in the West, must appear absurd to the majority of people, who have little or no access to mental health services. The appalling stigma still attached to mental illness, however, is a reality throughout the world.

For much of the past century (unlike the century preceding it) psychodynamic causal explanations held sway in psychiatric practice. Over the past 20--30 years the biological contribution to much mental illness has been rediscovered and biological approaches to treatment and research have enjoyed hegemony over other paradigms. The experiences of illness and its treatment, however, always occur in a social context and it is vital that this perspective is not forgotten as evidence of biological contributions to illness accrue. There are those who adopt a narrow-minded belief system in which only one particular approach to understanding is deemed possible or acceptable. Such extremist positions are illinformed, naive and extremely detrimental both to research and patient care. It is essential to appreciate that it is possible, and indeed helpful, to seek an understanding at different levels of analysis (e.g. molecules, neurons, brain regions, neuronal networks, psychological mechanisms, family groups, social groups and populations) and that understanding at one level is likely to inform understanding at other levels. Models of psychiatric disorders that integrate such diverse findings will be of enormous benefit - both academically and, more importantly, clinically.

The fact that mental illness can run in families has been known for some considerable time but until recently was of academic interest only. Modern molecular genetics provides methods by which susceptibility genes for major psychiatric disorders may be found and it is possible that a number of susceptibility genes will be discovered for the major mental illnesses in the early years of this decade - a task that will be considerably facilitated by the completion of the human genome project (discussed in Craddock \& Jones, 1999). Genetics has proved a powerful tool in the investigation of single gene disorders. The task that remains is to apply the developing methodologies to uncover the pathophysiology of complex disorders such as cardiovascular disease, diabetes and major psychiatric illness (Craddock \& Owen, 1996). Complex disorders result from the interaction of many susceptibility genes and environmental influences. Rather than rare mutations, the susceptibility genes involved are likely to be common variations (polymorphisms) in the population. Susceptibility genes do not act in a deterministic, all-or-nothing manner, but rather as a complex interaction of genes and environment that alter the risk of developing a disorder.

\section{Opportunities}

There are a number of positive implications for the discovery of susceptibility genes for mental illness (reviewed in Craddock et al, 1999). An improved understanding of aetiological mechanisms is likely to lead to the development of improved classification systems and better, more targeted treatments. It is likely to be possible to predict the response and side-effects of various treatments based on an individual's genotype, so called 'pharmacogenetics' (Wolf et al, 2000). Preventative strategies are likely to become better informed - for example, it may be possible to identify genotypes associated with an increased risk of acute psychotic episodes being precipitated through the use of illicit drugs. Genotype may also predict prognosis and influence decisions regarding the use of prophylactic strategies. Such developments have the potential to become a reality in the relatively near future for Alzheimer's disease, a disorder 
for which several genes have already been identified that influence susceptibility.

Although the main motivation to search for

opinion

\& debate

susceptibility genes for psychiatric disorders is to increase understanding of pathophysiology, and thereby improve the management of individuals with illness, with the identification of such genes comes the potential for presymptomatic and prenatal testing. Whether this development will occur remains unclear, but theoretically it may be possible and therefore the issue of testing needs to be considered. For single gene disorders it has usually proved easier to develop tests than to devise effective interventions. However, until useful therapeutic options are available it is not clinically useful and may even be unethical to offer testing (Parens \& Asch, 1999).

However, even at our present level of knowledge there is much evidence to suggest that major psychiatric disorders, such as schizophrenia and bipolar disorder, benefit from early recognition and aggressive treatment (Jamison, 1998). Predictive testing for psychiatric illness need not, therefore, lead to therapeutic pessimism, but could bring great benefits to those at risk. Certainly sufferers themselves, when surveyed, show overwhelmingly positive attitudes towards the development of tests and a high hypothetical demand if such tests were available (Smith et al, 1996; Jones et al, 1997; Trippitelli et al, 1998), although, ethically, this should be seen alongside the wishes of those who claim the right to genetic ignorance (Takala, 1999).

\section{Challenges}

Few would argue against seeking a better understanding of the pathological basis of psychiatric disorders.

However, a number of potentially difficult issues are raised by the possibility of testing and need to be thought through carefully and the issues of presymptomatic and prenatal testing are undoubtedly the most problematic. Should the testing of children and young people under 18 years be prohibited (Hoffmann \& Wulfsberg, 1995; Cohen, 1998) even though conditions such as bipolar disorder and schizophrenia frequently have onsets in the teenage years and may be amenable to preventative strategies or early intervention? Perhaps most contentiously, should therapeutic abortion be allowed under any circumstances owing to risk of the foetus suffering mental illness in later life? There is much evidence of a link between disorders such as manic depression and creativity (Jamison, 1998). Seeking to eliminate genes that predispose people to major mental illness could have unforeseen and onerous consequences.

There are also issues regarding who should have the right to genetic information. It is possible to foresee scenarios in which discrimination by employers, insurance companies and health care providers result from an individual's genotype (Gevers, 1993). Additional dilemmas with regards to genetic testing exist, for example, where would counselling for genetic testing for common disorders be provided? Genetic services within the UK are currently provided within regional centres under a considerable workload. Owing to resource implications it will be necessary for counselling and testing for common complex disorders to be provided at the level of primary care or the district hospital (Kinmonth et al, 1998). Are these local services willing or able to take on the potential increase in workload? There is also the potential for commercial exploitation of testing for susceptibility genes for common disorders (Resnik, 1997). With so many families affected by these illnesses, there are vast potential profits to be made offering testing over-the-counter or even by post. Counselling and testing for genetic disorders also have implications for other family members. Is there a moral duty to inform other family members of potential risk, possibly against the wish of the initially tested individual, or would this be regarded as a breach of confidentiality (Wertz \& Fletcher, 1991)? It is important to realise that most of these issues are not specific to mental illness but apply equally to the large number of common familial disorders with a genetic contribution (e.g. heart disease, diabetes, asthma and hypertension).

Perhaps the most difficult issues raised by these advances regard the understanding of our humanity and concepts such as free will (Kant, 1993) and determinism. There is a risk of over-estimating the role of genes, leading to a genetic determinism that denies the moral accountability of the individual and results in the medicalisation of social deviance. Alternatively, the problems of society may be viewed as the consequence of individual genotypes, those in power abrogating responsibility for inequality and misusing science to defend the status quo. In order to avoid the nihilism that results from genetic determinism, it is important that these misconceptions are addressed.

\section{Stigma}

If presented in a balanced way, an increased understanding of the biological contributions to psychiatric illness is likely to act as a major destigmatising force. However, if not handled sensibly, the discovery of susceptibility genes has the potential to increase stigma for those suffering from mental illness - the 'double whammy' of 'madness' plus the 'bad blood' of a genetic disorder. Alternatively, it may be argued that 'genetic' conditions are not uniformly viewed negatively and the case of human immunodeficiency virus infection illustrates that stigmatisation occurs in diseases with diverse aetiologies. It is lay-models of psychiatric illness (such as moral weakness or the judgement of God) in addition to some previously advocated by professionals (e.g. the schizophrenogenic mother) that have resulted in the unacceptable levels of stigma that mental illness currently attracts.

\section{Conclusions}

Criticism of psychiatric genetics verges simultaneously from statements that this is a conceptually flawed project that will never discover susceptibility genes because they 
do not exist, to the seemingly incompatible view that finding genes will usher in an age of increased stigma and discrimination. We believe that susceptibility genes will be found and that this will bring great benefits in terms of increased understanding of pathophysiology. Finding susceptibility genes has the potential to help us meet many of the challenges facing psychiatry in the new millennium. The prospect is of an aetiologically-based classification system, superior treatment options and improved prediction of prognosis and treatment response. Such developments would have enormous implications for service delivery and it is possible that policy decisions made today regarding service delivery may need to be radically rethought in light of such a revolution in therapeutic potential.

Major advances raise major ethical issues and it is important to consider the implications of likely future advances. The recent report of the Nuffield Council on Bioethics into the ethical context of advances in psychiatric genetics represents an important first step in stimulating debate (Nuffield Council on Bioethics, 1998). It is vital that a balanced perspective is adopted if those suffering from mental illness are to be both protected from exploitation and allowed to benefit from the possible advantages that advances may bring.

\section{References}

COHEN, C. B. (1998) Wrestling with the future: should we test children for adult-onset genetic conditions? Kennedy Institute of Ethics Journal, $\mathbf{8}$ $111-130$.

—\& JONES, I. (1999) Genetics of bioplar disorder. Journal of Medical Genetics, 36, 585-594.

CRADDOCK, N. \& OWEN, M. J. (1996) Modern molecular genetic approaches to psychiatric disease. British Medical Bulletin, 52, 434-452.
GEVERS, S. (1993) Use of genetic data, employment and insurance: an international perspective. Bioethics, $\mathbf{7}$, 126-134.

HANAUSKE-ABEL, H. M. (1996) Not a slippery slope or sudden subversion: German medicine and national socialism in 1933. British Medical Journal, 313, 1453-1463.

HOFFMAN, D. E. \& WULFSBERG, E. A. (1995) Testing children for genetic predispositions: is it in their best interests? Journal of Law, Medicine and Ethics, 23, 331-344.

JAMISON, K. R. (1998) Stigma of manic depression: a psychologist's view. Lancet, 352, 1053.

JONES, I. \& CRADDOCK, N. (1997) The crisis in psychiatry. Lancet, 349, 155.

— \& - (1998) Ethical issues in genetics of mental disorders. Lancet, 352, 1788.

—, SCOURFIELD, J., MCCANDLESS, F. \&

CRADDOCK, N. (1997) Testing for

bipolar disorder susceptibility genes:

the patients perspective. American Journal of Medical Genetics, 74, 594.

KANT, I. (1993) The Moral Law. Groundwork of the Metaphysic of Morals. (Translated by H. J. Paton) London and NewYork: Routledge.

KINMONTH, A. L., REINHARD, J., BOBROW, M., et al (1998) The new genetics: implications for clinica services in Britain and the United States. British Medical Journal, 316 767-770.

MCGLEENAN, T. (1995) Human gene therapy and slippery slope arguments. Journal of Medical Ethics, 21, 350-355.
NUFFIELD COUNCL ON BIOETHICS (1998) Mental Disorders and Genetics: the Ethical Context. London: Nuffield Council on Bioethics.

PARENS, E. \& ASCH, A. (1999) The disability rights critique of prenatal genetic testing. Hastings Center Report, 29, (Suppl.), S1-S22.

RESNIK, D. B. (1997) The morality of human gene patents. Kennedy Institute of Ethics Journal, 7, 43-61.

ROSE, S. P. R. (1998) Neurogenetic determinism and the new euphenics. British Medical Journal, 317, 1707-1708.

SEIDELMAN,W. E. (1996) Nuremberg lamentation for the forgotten victims of medical science. British Medical Journal, 313, 1463-1467.

SMITH, L. B., SAPERS, B., REUS, V. I., et al (1996) Attitudes towards bipolar disorder and predictive genetic testing among patients and providers. Journal of Medical Genetics, 33, 544-549.

TAKALA, T. (1999) The right to genetic ignorance confirmed. Bioethics, 13 288-293.

TRIPPITELLI, C. L., JAMISON, K. R. FOLSTEIN, M. F., et al (1998) Pilot study on patients' and spouses' attitudes toward potential genetic testing for bipolar disorder. American Journal of Psychiatry, 155, 899-904.

WERTZ, D. C. \& FLETCHER, J. C. (1991) Privacy and disclosure in medical genetics examined in an ethics of care. Bioethics, 5, 212-232.

WOLF, C. R., SMITH, G. \& SMITH, R. L. (2000) Pharmacogenetics. British Medical Journal, 320, 987-990.
Ian Jones WellcomeTrust Research Fellow in Mental Health， Lindsey Kent* WellcomeTrust Research Fellow in Mental Health, Division of Neuroscience, University of Birmingham, Queen Elizabeth Psychiatric Hospital, Birmingham, B15 2QZ, Moli Paul Consultant Child Psychiatrist, Invicta Community Care NHS Trust, Dartford, Nick Craddock WellcomeTrust Senior Research Fellow in Clinical Sciences, Professor of Molecular Psychiatry \& Honorary Consultant Psychiatrist 